\title{
Sensitivity of mycelial growth of mushroom Agrocybe semiorbicularis to different concentrations of different disinfectants
}

\author{
Toma Buba ${ }^{1 *}$, Veronica Agbo ${ }^{2}$, Aliyu AbDUllahi ${ }^{3}$, Joseph Emmanuel ${ }^{3}$ \\ ${ }^{1}$ Department of Ecology, Faculty of Science, Abubakar Tafawa Balewa University, Bauchi, Nigeria \\ ${ }^{2}$ Department of Microbiology, Abubakar Tafawa Balewa University, Bauchi, Nigeria \\ ${ }^{3}$ Department of Biological Science, Abubakar Tafawa Balewa University, Bauchi, Nigeria
}

\begin{abstract}
This study was performed to determine the effects of different types of disinfectants (Hypo, Izal, and Dettol) on the mycelial growth of the mushroom Agrocybe semiorbicularis. The more evolutionarily advanced mushroom mycelium was expected to show greater resistance to disinfectants than other fungal and bacterial contaminants. Minimal disinfectant concentration was the one at which contaminants were inhibited, while the growth of the desired mushroom mycelia remained unaffected. Different concentrations of different disinfectants were added to the growth media, and the pure mushroom mycelial culture was inoculated on the media and left to grow. The results revealed that the probability of contamination was higher in all the concentrations of Hypo and in lower concentrations of Dettol and Izal. At 5\% concentration of the disinfectants (Hypo, Izal, and Dettol), the mean values of contamination were $0.667,0.417$, and $0.00(P<0.001)$, respectively. At $10 \%$ concentration, the mean contamination values were $0.167,0.583$, and $0.333(P>0.05)$, respectively, while at $15 \%$ concentration, the mean contamination values were $1.000,0.417$, and $0.250(P<0.05)$, respectively. At higher concentrations of the disinfectants, the growth of contaminants was completely suppressed, and the growth of the desired mycelia was also significantly decreased. At $17 \%$ concentration of the disinfectants (Hypo, Izal, and Dettol), the mean values of contamination were $0.833,0.833$, and $0.00(P<0.05)$, respectively. At $18 \%$ disinfectant concentration, the mean contamination values were $0.167,0.00$, and $0.00(P>0.05)$, respectively, while at $20 \%$ disinfectant concentration, the mean contamination values were $0.583,0.00$, and $0.00(P<0.05)$, respectively. The mean values of the mushroom's mycelial growth for the three disinfectants (Hypo, Izal, and Dettol) were 6.26, 15.38, and $21.93 \mathrm{~mm}(P<0.05)$, respectively, for 5\% concentration; $11.75,10.08$, and $13.90 \mathrm{~mm}(P>0.05)$, respectively, for $10 \%$ concentration; and $0.00,12.88$, and $18.33 \mathrm{~mm}(P<0.05)$, respectively, for $15 \%$ concentration. At higher concentrations of the disinfectants (Hypo, Izal, and Dettol), the mean values of the mushroom's mycelial growth were $16.92,11.90$, and $14.33 \mathrm{~mm}(P>0.05)$, respectively, for $17 \%$ concentration; $18.54,3.00$, and $8.71 \mathrm{~mm}$ $(P>0.05)$, respectively, for $18 \%$ concentration; and $13.50,13.25$, and $0.00 \mathrm{~mm}(P>0.05)$, respectively, for $20 \%$ concentration. Disinfectants that yielded $100 \%(12 / 12)$ growth of pure cultures were $18 \%$ and $20 \%$ concentrations of Izal and 15\% concentration of Dettol $(P<0.05)$. Dettol at concentrations of $10 \%, 17 \%$, and $18 \%$ yielded $66.7 \%$ $(8 / 12)$ of pure cultures, but with a significant decrease in growth $(P<0.05)$ and viability; moreover, no contaminants survived at these concentrations. In general, mushroom mycelia were found to exhibit a higher degree of resistance to disinfectants than fungal and bacterial contaminants. Pure mycelial cultures were obtained in almost all the concentrations of all the disinfectants, but there were trade-offs between the levels of contaminations and better growth of the desired mycelia. Dettol was found to have the highest effect on suppressing contaminant growth followed by Izal and the least effective was Hypo. The result of this study will help in the process of mushroom production by reducing the problems of contamination.
\end{abstract}

Key words: Agrocybe, contamination, disinfectant, Dettol, mycelia, mushroom

\footnotetext{
* Corresponding author: Department of Ecology, Faculty of Science, Abubakar Tafawa Balewa University, Bauchi. PMB 0248, Bauchi State, Nigeria; e-mail: tomabuba@gmail.com
} 


\section{Introduction}

Mushrooms are spore-bearing distinctive fruiting bodies of macrofungi that are produced above ground or on other growth substrates (Wani et al., 2010; Kumar, 2015). Generally, mushrooms are useful in economic, medicinal, and ecological applications. They have been used as food, medicine, and cosmetics in different parts of the world for centuries. Some mushroom species are sources of bioactive compounds such as ascorbic and organic acids, alkaloids, carotenoids, enzymes, flavonoids, folates, glycosides, lectins, and phenolics, which afford them medicinal properties (Kalac, 2013; Kumar, 2015; Valverde et al., 2015). Some mushrooms are ectomycorrhizal fungi that play important environmental and ecological roles. They form mutualistic relationships between plant roots and specific fungi (Rossi et al., 2007). Ectomycorrhizas provide the plants with efficient water and nutrient uptake, while the fungus obtains photosynthates from the plant (Jha and Kumar, 2011; Klavina, 2015; Torres-Aquino et al., 2017). Hence, they improve agricultural productivity in nutrient-deficient soils (Hrynkiewicz and Baum, 2011). Additionally, some ectomycorrhizas are found to be efficient in preventing uptake and accumulation of heavy metals in plant tissues and are therefore used for reclaiming soils contaminated with heavy metals (Ingrid, 2011; Nanda and Abraham, 2013). However, for practical and extensive exploitation of the benefits of mushrooms, their artificial production is necessary. The business of mushroom production provides job opportunities, thereby providing an alternative source of income in many countries (Celik and Peker, 2009).

Generally, the cultivation of useful fungi involves obtaining pure mycelia culture of the fungi, followed by the preparation of spawn (Bankole and Salami, 2017). The first critical stage of successful cultivation of any mushroom is the production and maintenance of absolutely pure mycelial culture and spawn. Growth of mushroom mycelial culture is highly affected by several factors such as growth media, $\mathrm{pH}$, temperature, moisture content, high relative humidity, and light intensity. The environmental conditions that are optimal for the growth of mushroom mycelia are also, however, ideal for the growth of microbial contaminants (László et al., 2010; Sardar et al., 2015). Maintaining a suitable environment and controlling the contamination during spawn production are extremely difficult and labor-intensive (Uddin,
2012). The process of suitable spawn production requires several operations that are carefully performed in absolute hygiene conditions to avoid any contamination. These requirements make it a highly technical process that requires specialized scientific facilities and equipment (Sánchez, 2004; Rosmiza et al., 2016).

The minimal requirements for proper spawn production include laboratory equipment such as pressure cooker, autoclave, and inoculation box or laminar air flow cabin, which are commonly available in hospitals, research institutions, and universities (Van Nieuwenhuijzen, 2007; Dias, 2010). Developed countries usually employ computerized environmental control systems that are capable of monitoring environmental parameters and thereby increase the production of mushroom cultures at relatively low cost (Sánchez, 2004). In developing countries, mushroom growers use low technology because the knowledge is too complex, equipment for maintaining spawn production is very expensive, and the process is time-consuming (Kües, 2007; Ndem and Martha, 2016).

Obtaining pure mycelial cultures and the subsequent spawn are the major limiting factors to mushroom cultivation in developing countries (Sardar et al., 2015). The process requires practical exclusion of other contaminant microorganisms, involving strict hygiene conditions that are generally too costly and impractical to operate on a large scale especially in low income countries. Unfortunately, any failure to achieve a satisfactory harvest may often lead to heavy loss in mushroom production (Choi et al., 2010; Bellettini et al., 2016; Chang and Wasser, 2017). The contaminants exhibit fast growth and usually out-compete the mycelia of mushrooms for space and nutrients. The contaminants also produce extracellular enzymes and other toxic secondary compounds that can result in a significant decrease in mushroom biomass production or even entirely eliminate it (Mwangi et al., 2017). To prevent contamination, various treatments are used for the preparation of cultures to inhibit competitive fungi, which include disinfection treatments applied to growth substrates at different production phases. For this purpose, the minimal inhibitory concentrations of the disinfectant have to be determined first (László et al., 2010; Colavolpe et al., 2014). Hence, mushroom growers usually obtain their spawn from producers such as universities and other research institu- 
tes, which limit their production capacities. These requirements and other technical challenges undoubtedly restrict mushroom production especially in developing countries (Van Nieuwenhuijzen, 2007; Dias, 2010). To boost mushroom production, it is therefore necessary to find cheaper and easier methods of controlling contaminations, so that ordinary small-scale mushroom growers can produce their own spawn (Van Nieuwenhuijzen, 2007).

Mushrooms belong to the phylum Basidiomycota, and they are considered to be the most complex and evolutionarily advanced members of the fungi kingdom. Their hyphae are uniquely different from those of all other fungi species, with highly characteristic features and "cellular" compositions (Oberwinkler, 2012; De MattosShipley et al., 2016). The present study aimed to determine the effects of different types of disinfectants on the mycelial growth of the mushroom Agrocybe semiorbicularis. Specifically, the study's objective was to determine the minimal concentration of these disinfectants that can inhibit contaminants and at the same time does not affect the growth of the desired mushroom mycelia. We predicted that the mushroom mycelia, being the most complex and evolutionarily advanced, will also show a higher degree of resistance to disinfectants than other fungal and bacterial contaminants.

\section{Materials and methods}

\section{Collection of mushrooms}

Sporocarps (fruiting bodies) of $A$. semiorbicularis (family: Strophariaceae) were collected from the wild in the rainy season and transported in plastic bags. The specimens were cleaned of debris and then sun-dried for 5 days. After drying, the specimens were put inanairtight polythene bag and stored in a cardboard box at room temperature until use (Fig. 1).

\section{Obtaining pure mycelial culture}

Three different media were initially used to obtain the pure mycelial culture and to ascertain the best media for mycelia growth (Peksen et al., 2013; Mahadevan and Shanmugasundaram, 2018). The media used were malt extract agar $\left(\right.$ Accumix $^{\mathrm{TM}}$ ), yeast extract agar (Accu$\mathrm{mix}^{\mathrm{TM}}$ ), and potato dextrose agar (PDA, TM Media ${ }^{\mathrm{TM}}$ ). They were prepared according to the manufacturer's instructions. The media were autoclaved at $1.1 \mathrm{~kg}_{\mathrm{f}} / \mathrm{cm}^{2}$ $\left(121^{\circ} \mathrm{C}\right)$ for $20 \mathrm{~min}$. To suppress bacterial growth, chlor

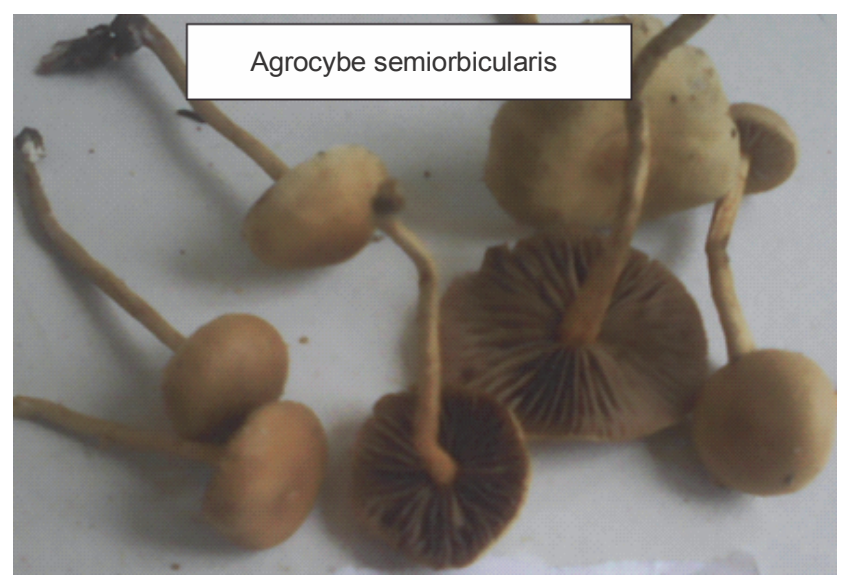

Fig. 1. Mushroom species used in the study

amphenicol $(0.03 \mathrm{~g} / \mathrm{l})$ was added to the media at $45^{\circ} \mathrm{C}$. Approximately $20 \mathrm{ml}$ of the media was then poured into Petri dishes $(90 \times 15 \mathrm{~mm})$ inside a sterilized laminar flow hood and subsequently solidified (Mendoza et al., 2014). The mushroom samples were then surface sterilized by spraying $70 \%$ ethanol and cut into pieces (approximately $1 \mathrm{~cm}^{2}$ ) with a sterile scalpel. The pieces were then placed with a pair of forceps in the prepared media in a way such that their gills were in direct contact with the media. The mushrooms placed on Petri dishes were then incubated at $28^{\circ} \mathrm{C}$ in complete darkness. After 4-7 days, the mycelia were subcultured into new Petri dishes to obtain a pure mycelial culture. Pure mycelia in Petri dishes without contamination were used for the experiment. PDA was finally adopted as the preferred growth media for the subsequent experiments.

\section{Preparation of media and disinfectants and inoculation of mycelia}

The disinfectants used for the experiment were Dettol $^{\circledR}$ (chloroxylenol), Hypo ${ }^{\circledR}$ (sodium hypochlorite), and $\mathrm{Izal}^{\circledR}$. These are some of the most commonly used disinfectants in this region (Chima et al., 2013). Different concentrations of disinfectants were prepared using distilled water: $5,10,15,18$, and $20 \%$ and control (distilled water). Ten milliliters of each of the different concentrations of the disinfectants were aseptically added to $200 \mathrm{ml}$ (1:20 disinfectant/media ratio) of the prepared PDA growth media in conical flasks at $45^{\circ} \mathrm{C}$ and then vigorously shaken to homogenize. Twenty milliliters of the media were poured into Petri dishes and solidified. Actively growing mycelia were taken at 10 days from the 
periphery by using a cork borer and placed on two points of each Petri dish $(90 \times 15 \mathrm{~mm})$. To increase the probability of normal aerial contamination, the inoculation was not performed inside the laminar flow hood. Each treatment was replicated in six Petri dishes. The Petri dishes were incubated in complete darkness at $28^{\circ} \mathrm{C}$ for 7 days. The optimal concentrations of disinfectants for mycelia growth were determined by measuring colony diameters (Luangharn et al., 2014; Mendoza et al., 2014).

\section{Measurements and data collection}

The growth-colony radius of radial mycelia was recorded using a ruler across the Petri dish (Mahadevan and Shanmugasundaram, 2018; Sharma et al., 2018). The size of the growth-colony radius was estimated by measuring the vertical and horizontal diameters of the mycelia. The sum of the radial measures in millimeter $(\mathrm{mm})$ was divided by four (4) and was regarded as the radial growth for each of the concentrations of the disinfectants (Chima et al., 2013). The level of contamination was taken as the ratio between the numbers of contaminated cultures and the total number of cultures, which were 12 . The values ranged from 0.00 to 1.00 . Viability of the mushroom mycelia was also taken as the ratio between the number of growing mushroom mycelia inoculums and the total number of inoculums. Here, the values ranged from 0.00 to 1.00 .

\section{Data analysis}

The data obtained were subjected to analysis of variance (ANOVA) followed by Tukey's Multiple Comparisons of means using Minitab ${ }^{\circledR} 18.1$.

\section{Results}

\section{Effects of different concentrations of different disinfectants on mycelial growth}

The results of this study show that the rate of the mushroom's mycelial growth, contamination, and the viability of the hyphae from the original mycelia plug inoculums differed depending on concentrations of various disinfectants (Fig. 2). The results also confirmed that mushroom mycelia, being the most complex and evolutionarily advanced, also have a higher degree of resistance to disinfectants than other fungal and bacterial contaminants. At $5 \%$ concentration of disinfectants (Hypo, Izal, and Dettol) in standard of 1:20 ml disinfectant/media ratio, the mean radial growth of mycelia co- lony for Dettol and Izal were significantly $(P=0.00 ; \alpha=$ 0.05 ) higher than that for Hypo (Table 1$)$. The mean values of the radial growth for Dettol, Izal, and Hypo were $21.93,15.38$, and $6.26 \mathrm{~mm}$, respectively. All the original mycelia plug inoculums were viable at the time of measurements, but the extent of contamination was significantly higher in Izal and Hypo than in Dettol. All the mycelia cultures in Dettol were pure, i.e., there were no contaminations. This clearly shows that the reduced mycelial growth in Izal and Hypo is due to high rate of the contamination. At $10 \%$ concentration of all the three disinfectants, there were no significant differencesin contamination and viability of the hyphae (Table 1 ). The mean contamination values were $0.167,0.583$, and 0.333 $(P=0.106)$, respectively. For the mycelial growth, the mean values were11.75, 10.08, and $13.90 \mathrm{~mm}$ $(P=0.623)$ for Hypo, Izal, and Dettol, respectively; their mean viability values were $0.583,0.667$, and 0.667 $(P=0.895)$, respectively.

Significant differences were observed in the rate of the mushroom's mycelia growth, contamination level, and the viability of the hyphae from the original mycelia plug inoculums across all the different disinfectants at $15 \%$ concentration. There was a significant decrease in mycelia growth $(0.00 \mathrm{~mm})$ and increase in contamination (1.00) in Hypo $(P=0.000)$, and decrease in hyphae viability in Izal, which was $0.583(P=0.002)$ (Table 1$)$. At $17 \%$ concentration of Dettol, there was a significant decrease in contamination (0.00) and viability of hyphae (0.583). Decrease in mycelial growth $(14.33 \mathrm{~mm})$ was also observed but not statistically significant $(P=0.462)$. This suggests that the decrease in mycelia growth was due to higher concentration of the disinfectants rather than suppression by the competitive contaminants (Table 1).

At $18 \%$ concentration of disinfectants, there was a significant decrease in mycelia growth and hyphae viability in Dettol, while contaminations were completely absent (Table 1). The mean values for the growth, viability, and contaminations were $8.71 \mathrm{~mm}, 0.583$, and 0.00 , respectively. When using Izal as disinfectant, no contamination has been noted, mycelia growth decreased but viability of hyphae remained significantly high. The mean values for the growth, viability, and contaminations were $3.00 \mathrm{~mm}, 1.00$ and, 0.00 , respectively. The usage of Hypo led to insignificant presence of contaminants but significantly high rate of mycelia growth and 

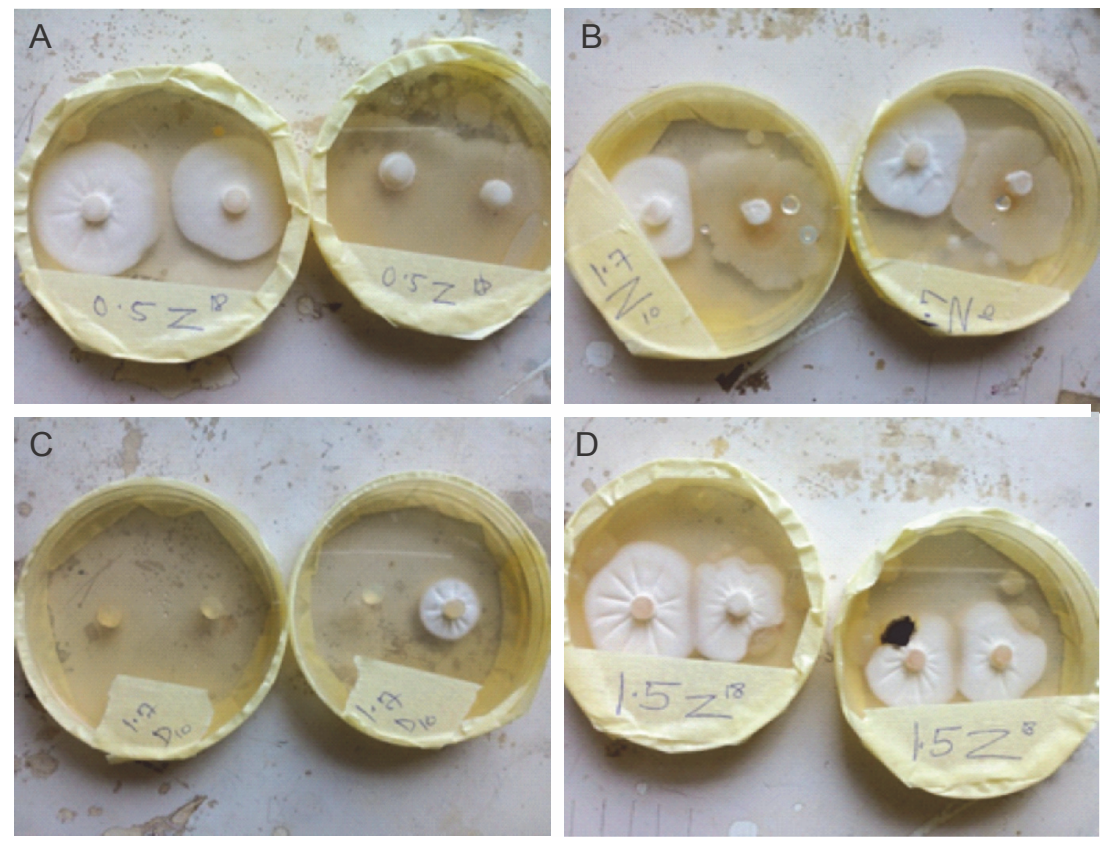

Fig. 2. A) mushroom mycelial growth showing pure mycelial culture and suppressed growth by bacteria in two different plates, and B) in the same plate; C) complete inhibition of growth (nonviable hyphae) and suppression of growth by disinfectant; D) effect of fungal and bacterial contaminants on the shape of mycelial growth pattern

Table 1. Mean values of the effect of 5, 10, 15, 17, 18, and 20\% concentrations of disinfectants (Hypo, Izal, and Dettol) on Agrocybe semiorbicularis mycelia in 1:20 $\mathrm{ml}$ disinfectant/media ratio; significance level $(\alpha)=0.05$

\begin{tabular}{l|c|c|c|c|c|c|c}
\hline \multicolumn{1}{c|}{ Factor } & & $5 \%$ & $10 \%$ & $15 \%$ & $17 \%$ & $18 \%$ & $20 \%$ \\
\hline Growth radius [mm] & $\mathrm{N}$ & mean & mean & mean & mean & mean & mean \\
\hline Hypo & 12 & $6.26^{*}$ & 11.75 & $0.00^{*}$ & 16.92 & $18.542^{*}$ & $13.50^{*}$ \\
\hline Izal & 12 & 15.38 & 10.08 & 12.88 & 11.90 & 3.000 & 13.250 \\
\hline Dettol & 12 & 21.93 & 13.90 & 18.33 & 14.33 & 8.71 & 0.000 \\
\hline Contamination [count] & & & & & & & \\
\hline Hypo & 12 & $0.667^{*}$ & 0.167 & $1.000^{*}$ & $0.833^{*}$ & 0.167 & $0.583^{*}$ \\
\hline Izal & 12 & 0.417 & 0.583 & 0.417 & 0.833 & 0.000 & 0.000 \\
\hline Dettol & 12 & 0.000 & 0.333 & 0.250 & 0.000 & 0.000 & 0.000 \\
\hline Viability [count] & & & & & & & \\
\hline Hypo & & & 0.583 & $1.000^{*}$ & $0.92^{*}$ & $1.000^{*}$ & $1.000^{*}$ \\
\hline Izal & & & 0.667 & 0.583 & 1.000 & 1.000 & 1.000 \\
\hline Dettol & & & 0.667 & 1.000 & 0.583 & 0.583 & 0.000 \\
\hline
\end{tabular}

${ }^{*} P<0.05$

viability of hyphae. Here, the mean values were 18.54 for the growth, 1.00 for viability, and 0.167 for the contaminations. In $20 \%$ concentration of Dettol, no contamination, no viability of mycelia and therefore, no growth were noted, and at the same concentration, there was viability of hyphae and mycelia growth in Hypo and Izal; moreover, there was significant contamination in Hypo but no contamination in Izal $(P=0.000)$ (Table 1$)$. The 
Table 2. Number of pure mycelial cultures and their growth obtained using different concentrations of disinfectants (Hypo, Izal, and Dettol) in growth media; significance level $(\alpha)=0.05$

\begin{tabular}{|c|c|c|c|c|c|c|c|c|c|}
\hline \multirow[b]{2}{*}{ Factor } & \multirow{2}{*}{$\begin{array}{c}\text { Pure } \\
\text { cul ture }\end{array}$} & \multirow[b]{2}{*}{ Percentage } & \multirow[b]{2}{*}{ Contamination } & \multicolumn{6}{|c|}{ Mycelia growth (mm) } \\
\hline & & & & $\mathrm{N}$ & mean & st. dev. & $\begin{array}{l}\text { pooled } \\
\text { st. dev. }\end{array}$ & $P$-value & $\mathrm{TPC}^{*}$ \\
\hline \multicolumn{10}{|l|}{ Hypo } \\
\hline $5 \%$ & 4 & 33.3 & 8 & 12 & 6.26 & 9.28 & 7.362 & 0.000 & $\mathrm{BC}$ \\
\hline $10 \%$ & 5 & 41.7 & 2 & 12 & 11.75 & 10.69 & & & $\mathrm{AB}$ \\
\hline $15 \%$ & 0 & 0.00 & 12 & 12 & 0.000 & 0.000 & & & $\mathrm{C}$ \\
\hline $17 \%$ & 2 & 16.7 & 8 & 12 & 16.92 & 8.94 & & & A \\
\hline $18 \%$ & 10 & 83.3 & 2 & 12 & 18.542 & 2.965 & & & $\mathrm{~A}$ \\
\hline $20 \%$ & 5 & 41.7 & 5 & 12 & 13.50 & 6.02 & & & $\mathrm{AB}$ \\
\hline \multicolumn{10}{|l|}{ Izal } \\
\hline $5 \%$ & 7 & 58.3 & 5 & 12 & 15.38 & 8.03 & 6.987 & 0.001 & A \\
\hline $10 \%$ & 5 & 41.7 & 7 & 12 & 10.08 & 6.43 & & & $\mathrm{AB}$ \\
\hline $15 \%$ & 7 & 58.3 & 5 & 12 & 12.88 & 9.77 & & & A \\
\hline $17 \%$ & 2 & 16.7 & 8 & 12 & 11.90 & 9.50 & & & $\mathrm{~A}$ \\
\hline $18 \%$ & 12 & 100 & 0 & 12 & 3.000 & 0.798 & & & $\mathrm{~B}$ \\
\hline $20 \%$ & 12 & 100 & 0 & 12 & 13.250 & 0.892 & & & $\mathrm{~A}$ \\
\hline \multicolumn{10}{|l|}{ Dettol } \\
\hline $5 \%$ & 12 & 100 & 0 & 12 & 21.925 & 3.340 & 7.522 & 0.000 & A \\
\hline $10 \%$ & 8 & 66.7 & 4 & 12 & 13.90 & 10.93 & & & $\mathrm{AB}$ \\
\hline $15 \%$ & 9 & 75 & 3 & 12 & 18.33 & 4.48 & & & A \\
\hline $17 \%$ & 8 & 66.7 & 0 & 12 & 14.33 & 10.81 & & & $\mathrm{AB}$ \\
\hline $18 \%$ & 8 & 66.7 & 0 & 12 & 8.71 & 8.50 & & & $\mathrm{BC}$ \\
\hline $20 \%$ & 0 & 0.00 & 0 & 12 & 0.000 & 0.000 & & & $\mathrm{C}$ \\
\hline
\end{tabular}

* Tukey pairwise comparisons grouping information using the Tukey method and 95\% confidence intervals: means that do not share a letter are significantly different

values in both Hypo and Izal were 13.50 and $13.25 \mathrm{~mm}$ for growth, 0.58 and 0.00 for contamination, and 1.00 and 1.00 for viability.

\section{Disinfectants and their concentrations that yield desired mycelia growth}

According to the aim of this study, the desired results were to determine the optimum concentration of a disinfectant that yields pure mycelial culture with higher mycelial radial growth. Pure mycelial cultures were obtained in almost all the concentrations of all the disinfectants tested, although the probabilities of obtaining the pure mycelia culture differed with concentrations of the different disinfectants. There was, however, trade-off between levels of contaminations and the growth of the de- sired mycelia. Changes in the levels of contaminations were noted to be higher in all the concentrations of Hypo (5-20\%) and in the lower concentrations of Izal (5-17\%) (Table 1); furthermore, even in lower concentrations of Dettol (5-17\%), contaminations were significantly low. When higher concentrations of Dettol and Izal (18-20\%) were used for disinfection, contaminants were completely inhibited, but the growth of the desired mycelia was significantly decreased (Table 1 ). Percentages of growth of pure mushroom cultures obtained at $5 \%$ concentration of Hypo, Izal, and Dettol were 33.3, 58.3 , and $100 \%$, respectively, as compared to control. For $10 \%$ concentration, the percentages were $41.7,41.7$, and $66.7 \%$, respectively. At $15 \%$ concentration, the percentages of the growth of pure mushroom cultures were 


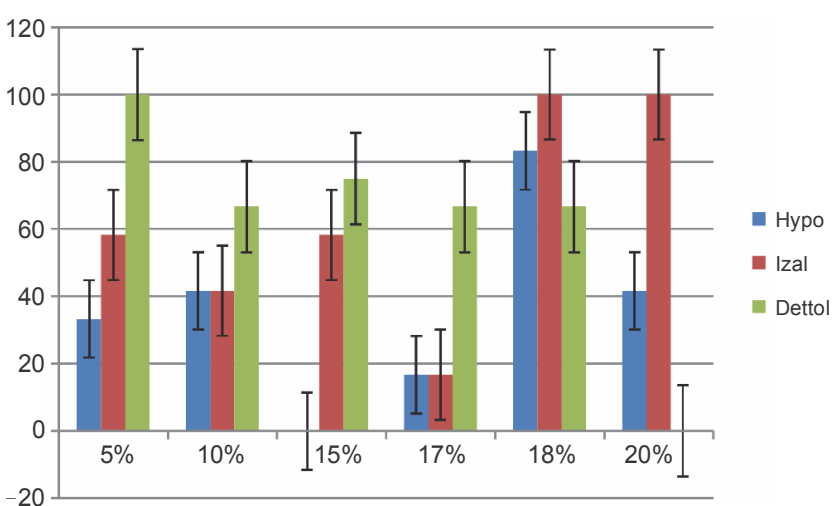

Fig. 3. Percentages of pure mycelial cultures obtained in different concentrations of different disinfectants (error bars with standard error)

$0.00,58.3$, and $75 \%$, respectively, while at $17 \%$ concentration, the growth percentages were $16.7,16.7$, and $66.7 \%$, respectively. For $18 \%$ concentration, the percentage growth of the pure mushroom culture was $83.3 \%$ for Hypo, $100 \%$ for Izal, and $66.7 \%$ for Dettol, while at $20 \%$ concentration, the percentage growth was $41.7,100$, and $0.00 \%$ for Hypo, Izal, and Dettol, respectively. Disinfectant concentrations that yielded $100 \%$ of pure cultures were $18 \%$ and $20 \%$ of Izal and $15 \%$ of Dettol (Table 2, Fig. 3). Dettol at concentrations of $17 \%$ and $18 \%$ yielded $66.7 \%$ of pure cultures, although there was a significant decrease in mycelia growth, which was 14.33 and $8.71 \mathrm{~mm}$ for $17 \%$ and $18 \%$ concentrations, respectively (Table 2, Fig. 4). Additionally, no contaminants survived these concentrations, and the viability of the desired mycelia decreased to 0.58 . The mycelial growth in Izal decreased significantly at these higher concentrations, but there was no contamination. The values of the mycelial growth in Izal at 17, 18, and 20\% concentrations were $11.90,3.00$, and $13.25 \mathrm{~mm}$, while that of contaminants were $0.00,0.00$, and 0.833 , respectively.

\section{Discussion}

This study revealed that the rate of the mushroom's mycelia growth, contamination, and the viability of the hyphae from the original mycelia plug inoculums differed with different concentrations of disinfectants used. The results also showed that mushroom mycelia, being the most complex and evolutionarily advanced component, have greater ability to survive higher concentrations of disinfectants than fungal and bacterial contaminants encountered in this study. The mushroom mycelia did

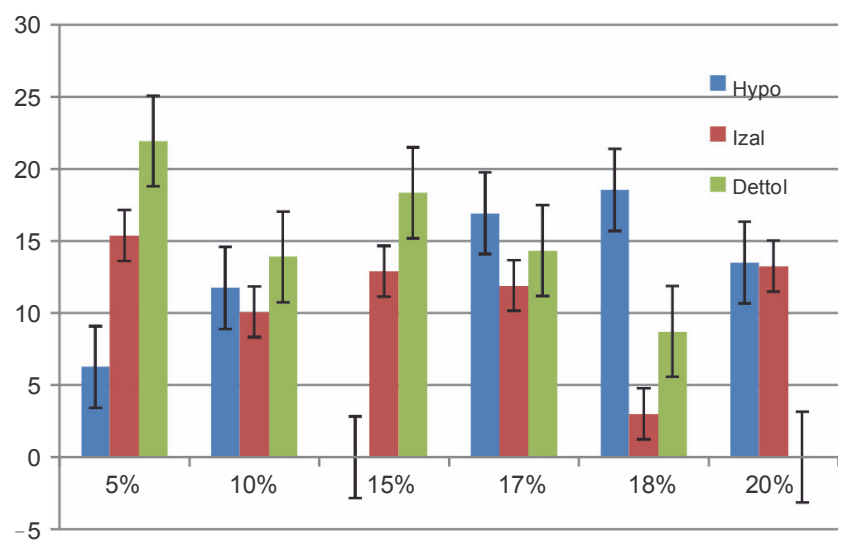

Fig. 4. Mycelial radial growth (mean) in different concentrations of different disinfectants (error bars with standard error)

not show any signs of growth due to microbial contamination in the media with no disinfectants, and the growth of the mushroom mycelia could not be measured. High levels of contaminations that suppressed the mycelial growth were observed at lower concentrations (5-15\%) of Izal and Hypo, but better mycelial growth and lower contaminations were observed in Dettol (Fig. 4). Similarly, Gargi et al., (2017) found that Dettol even at lower concentration is effective against some clinical pathogens (Escherichia coli, Staphylococcus aureus, Salmonella typhi) as is in the case of the present study. At higher concentrations (17-18\%), Dettol and Izal greatly inhibited the occurrence of contaminants (Table 2), with Dettol being the most effective as it completely inhibited all contaminants and still maintained mycelial growth. The viability of the mycelia was significantly inhibited by Dettol, but it remained almost unaffected when Izal was used at the same concentration (17-18\%). The effects of disinfectants on contaminants are known to decrease with a decreasing concentration of all disinfectants (Olasehinde et al., 2008; Gargi et al., 2017). The use of Hypo led to better mycelia viability and growth, but cases of contaminations were unfortunately higher. Compared to previous studies, there was no consistency in the effects of the three disinfectants on contaminants. Many similar studies on some pathogenic clinical isolates (E.coli, S. aureus, Salmonella typhi, and Aspergillus fumigatus) showed that Hypo has the least effect against the pathogens as compared to Dettol and Izal (Mattei et al., 2013; Okore et al., 2014; Gargi et al., 2017; Soyemi et al., 2018). However, other studies reported that Hypo was more effective than Dettol and Izal on the same orga- 
nisms (Al-Dabbagh et al., 2015; Shuaibu et al., 2017). AlDabbagh et al. (2015) found that $10 \%$ concentration of Hypo killed all the following bacterial isolates: E. coli, Pseudomonas aeruginosa, $S$. aureus, and Corynebacterium renali, while the same isolates showed greater resistance to Dettol. Moreover, some studies on fungi revealed that Hypo at concentrations between 0.03 and 2.4\% were effective at killing Penicillium, Cladosporium, Mucor, Rhizopus, Stachybotrys, Alternaria, Aspergillus, Helminthosporium, Trichophytonand Batrachochytrium spp. (Reynolds et al., 2004; Becker, and Gratwicke, 2017; Van Rooij et al., 2017).

There are possibly different factors that led to the different results of the effects of the disinfectants on microbial contamination and mushroom mycelia growth obtained in this study. First, disinfectants differ in their compositions and mode of actions against a wide range of microorganisms (McDonnell and Russell, 1999). For example, Dettol inhibits microorganisms by denaturation of the protein components of their cell wall and cytoplasmic membrane, while Hypo (sodium hypochlorite) affects microorganisms by oxidizing their cellular components such as protein, lipid, and nucleic acids (Al-Dabbagh et al., 2015). Second, the nature and composition of the microbial cell surfaces vary from one species to another; consequently, such surfaces could also be changed due to extremes of environmental conditions (McDonnell and Russell, 1999). As a result of differences in cellular structure, composition, and physiology, microbial contaminants can thus respond variedly to different concentrations of disinfectants (McDonnell and Russell, 1999; Singh et al., 2012; Hammond et al., 2014). While some disinfectants kill nearly all microorganisms, others kill only a smaller range of pathogens (Wijesinghe and Weerasinghe, 2010). Third, microorganisms can develop resistance to disinfectants. As Olasehinde et al. (2008) pointed out that dilution of disinfectants renders them less effective and thereby provides the target organisms the likelihood to develop resistance against the disinfectants used. Shuaibu et al. (2017) found that clinical pathogens developed resistance against Dettol, Izal and Hypo, with most resistance observed for Dettol and least resistance to Hypo. Additionally, microorganisms develop increased resistance to antibiotics and can share these disinfectant-resistant markers among themselves (Al-Dabbagh et al., 2015). Fourth, the efficacy of most disinfectants can be reduced by the amount of organic material that reacts with the available chemical components of the disinfectants, especially chlorine (Boothe, 1998; Shuaibu et al., 2017). More effective disinfection occurs when surfaces to be disinfected are free from organic matter and are smooth and nonporous (Boothe, 1998; Olasehinde etal., 2008). Finally, some disinfectants may fail to exert action as result of spoilage or improper storage (Shuaibu et al., 2017).

It was also observed that there is some level of inconsistencies in the result of this study with regard to Dettol and Hypo. For example, Dettol at 5\% concentration showed paradoxically more efficiency in controlling contamination than at both $10 \%$ and $15 \%$. There was also more contamination of cultures when Hypo was used at $20 \%$ concentration than at $18 \%$ concentration. These types of inconsistencies were also noted by Hammond et al. (2014), who reported that differences in contamination of culture can occur by chance. It should be noted that the sources of contamination in this research were not controlled and the contaminants were not identified; hence, the rate of the contamination of a particular culture was by chance. This implies that different microorganisms might have contaminated different cultures in various combinations. Different microorganisms usually have varied degrees of susceptibility to different disinfectants (Singh et al., 2012; Hammond et al., 2014). Additionally, microorganisms interact among themselves (Frey-Klett et al., 2011; Hiscox et al., 2018). These interactions lead to changes in species composition in a culture or natural environment. Interactions can occur for competition for nutrients, space, or inhibition. Fungal mycelia may interfere with the growth of another fungal species by physical contact and block their development of the hyphae through mycoparasitism or depletion of resource and consequently reduce nutrient availability. This may result in morphological changes in the hyphae or elimination of the inferior competitor depending on the fungal species composition (Lahlali and Hijri, 2010; Rogawansamy et al., 2015; Hiscox et al., 2018). Microorganisms that live in proximity compete for the same nutrients. Substrates that are rich in suitable nutrients are usually battlefields for both saprophytic bacteria and fungi (Künzler, 2018). Fungal mycelia may also produce organic compounds that are volatile or diffusible, or have the ability to alter the $\mathrm{pH}$ of the media, which have inhibitory effects on spore germination and growth of their competitors (Humphris et al., 2002; Lahlali and Hijri, 
2010; Hiscox et al., 2018). Many abiotic factors can also affect the outcomes of interactions between microorganisms, which could be of advantage or disadvantage to one another. However, even under apparently identical conditions, the outcomes of interactions are not always consistent, possibly due to immeasurably tiny differences in conditions (Hiscox et al., 2018). All these interactions might have affected the result of the present study in one way or the other through the environmentbacteria-fungi interactions. Nevertheless, the results of this study can be valuable for mushroom growers and producers of ectomycorrhizas as it show a cheaper and simple method of controlling contamination.

\section{Conclusions}

The present study found that the mycelia of the mushroom $A$. semiorbicularis have higher degree of resistance to disinfectants than other fungi and bacteria that contaminate growth media. This might be because mushrooms are known to be more complex and evolutionarily advanced species among fungi. This study also revealed that the rate at which mushroom's mycelia grow, the level of contamination of the growth media, and the viability of the mushroom's hyphae varied with different concentrations of different disinfectants used in the growth media. Pure mycelial cultures were obtained in almost all the different concentrations of all the disinfectants, although the percentages of these pure mycelial cultures obtained differed with different concentrations of all the disinfectants. However, trade-offs existed between the level of contamination and better growth of the desired mycelia. In general, the result of this study showed that Dettol has the highest effect on suppressing contaminants followed by Izal and the least effective was Hypo. This result will help in mushroom production processes by solving the problems of contamination.

\section{Acknowledgments}

We sincerely appreciate the Department of Ecology, Abubakar Tafawa Balewa University, Bauchi, and TETFUND Institutional Base Research for supporting us to conduct this research.

\section{Funding}

The present study was funded by TETFUND Institutional Base Research

\section{References}

Al-Dabbagh S.Y.A., Ali H.H., Khalil I.I., Hamad M.A. (2015) $A$ study of some antibiotics; disinfectants and antiseptics efficacy against some species of pathogenic bacteria. Assiut Vet. Med. J. 61(147): 210-217.

Bankole F.A., Salami A.O. (2017) Use of agro-wastes for tissue culture process and spawn production of oyster mushroom (Pleurotus florida). J. Appl. Life Sci. Internat. 14(1): 1-9.

Becker M.H., Gratwicke B. (2017) Minimum lethal concentration of sodium hypochlorite for the amphibian pathogen Batrachochytrium dendrobatidis. PLoS One, 12(4): e0176439. DOI: 10.1371/journal.pone.0176439.

Bellettini M.B., Fiorda F.A., Maieves H.A., Teixeira G.L., Ávila S., Hornung P.S., Júnior A.M., Ribani R.H. (2016) Factors affecting mushroom Pleurotus spp. Saudi J. Biol. Sci. DOI: 10.1016/j.sjbs.2016.12.005.

Boothe H.W. (1998) Antiseptics and disinfectants. Veterin. Clin. North Amer.: Small Animal Pract. 28(2): 233-248. DOI: 10.1016/j.jaci.2004.01.082.

Celik Y., Peker K. (2009) Benefit/cost analysis of mushroom production for diversification of income in developing countries. Bulgar. J. Agric. Sci. 15(3): 228-237.

Chang S.T., Wasser S.P. (2017) The cultivation and environmental impact of mushrooms. DOI: 10.1093/acrefore/ 9780199389414.013.231.

Chima I.U., Uchegbu M.C., Okoli I.C., Ezema C., Wehke S.N. (2013) Evaluation of the efficiency of disinfectants used against bacterial isolates from intensive poultry farming environments in Imo State, Nigeria. J. Biol. Sci. 13: 349-356. DOI: $10.3923 /$ jbs.2013.349.356.

Choi I., Choi J., Sharma P.K., Lee W. (2010) Isolation and identification of mushroom pathogens from Agrocybe aegerita. Mycobiology 38(4): 310-315. DOI: 10.4489/MYCO. 2010.38.4.310.

Colavolpe M.B., Mejía S.J., Albertó E.O. (2014) Efficiency of treatments for controlling Trichoderma spp during spawning in cultivation of lignicolous mushrooms. Brazil. J. Microbiol. 45(4): 1263-1270.

De Mattos-Shipley K.M.J., Ford K.L., Alberti F., Banks A.M., Bailey A.M., Foster G.D. (2016) The good, the bad and the tasty: the many roles of mushrooms. Stud. Mycol. 85: 125-157.

Dias E.S. (2010) Mushroom cultivation in Brazil: challenges and potential for growth. Ciência Agrotecnol. 34(4): 795-803.

Frey-Klett P., Burlinson P., Deveau A., Barret M., Tarkka M., Sarniguet A. (2011) Bacterial-fungal interactions: hyphens between agricultural, clinical, environmental, and food microbiologists. Microbiol. Mol. Biol. Rev. 75(4): 583-609. DOI: 10.1128/MMBR.00020-11.

Gargi R., Pimpliskar M.R., Vanmali H.S., Rahul J. (2017) Efficacy study of some antiseptics and disinfectants. Intern. J. Life Sci. 5(4): 593-598. 
Hammond R., Buah J.N., Asare P.A., Acheampong S. (2014) Optimizing sterilization condition for the initiation of sweet potato (Ipomoea batatas) culture in vitro. Asian J. Biotechnol. 6: 25-37. DOI: 10.3923/ajbkr.2014.25.37.

Hiscox J., O'Leary,J., Boddy L. (2018) Fungus wars: basidiomycete battles in wood decay. Studies Mycol. 89: 117-124.

Hrynkiewicz K., Baum C. (2011) The potential of rhizosphere microorganisms to promote the plant growth in disturbed soils. [in:] Environment protection strategies for sustainable development. 31-35. DOI: 10.1007/978-94-007-1591-2.

Humphris S.N., Bruce A., Buultjens E., Wheatley R.E. (2002) The effects of volatile microbial secondary metabolites on protein synthesis in Serpula lacrymans. FEMS Microbiol. Lett. 210(2): 215-219.

Ingrid L.D.I. (2011) Evaluation for a plant-assisted bioremediation approach: $\mathrm{Zn}(\mathrm{Cd})$ accumulation properties of indigenous poplar species and the impact of ectomycorrhizas on phytoextraction characteristics. A doctoral dissertation, Department of Forest and Soil Sciences, BOKU-University of Natural Resources and Life Sciences, Vienna: 68.

Jha S.K., Kumar N. (2011) Potential of mycorrhizal fungi in ecosystem: a review. Intern. J. Res. Bot. 1(1): 1-7.

Kalac P. (2013) A review of chemical composition and nutritional value of wild-growing and cultivated mushrooms. J. Sci. Food Agric. 93: 209-218. DOI: 10.1002/jsfa.5960.

Klavina D. (2015) Ectomycorrhizas of Norway spruce (Picea Abies (L.) Karst.) in managed forest stands of Latvia. Doctoral thesis submitted for the degree of doctor of biology, subfield: Ecology. University of Latvia, Faculty of Biology Latvian State Forest Research Institute "Silava".

Kües U. (2007) Wood production, wood technology, and biotechnological impacts. Universitätsverlag Göttingen: 635.

Kumar K. (2015) Role of edible mushroom as functional foodsa review. South Asian J. Food Technol. Environ. 1(3-4): 211-218.

Künzler M. (2018) How fungi defend themselves against microbial competitors and animal predators. PLoS Pathog. 14(9): e1007184.

Lahlali R., Hijri M. (2010) Screening, identification and evaluation of potential biocontrol fungal endophytes against Rhizoctonia solani $A G 3$ on potato plants. FEMS Microbiol. Lett. 311(2): 152-159. DOI: 10.1111/j.1574-6968.2010.02084.x.

László K., García J.L., Shahram N., Dorina C., Péter U., László M., Csaba V., Lóránt H. (2010) A challenge to mushroom growers: the green mould disease of cultivated champignons. [in:] Current research, technology and education topics in applied microbiology and microbial biotechnology. FORMATEX, Badajoz: 295-305.

Luangharn T., Karunarathna S.C., Hyde K.D., Chukeatirote E. (2014) Optimal conditions of mycelia growth of Laetiporus sulphureus sensu lato. Mycology 5(4): 221-227. DOI: 10.1080/21501203.2014.957361.

Mahadevan K., Shanmugasundaram K. (2018) Comparative effect of different culture media on mycelial growth performance of Pleurotus sapidus. J. Pharmacogn. Phytochem. 7(4): 874-878.
Mattei A.S., Madrid I.M., Santin R., Schuch L.F.D., Meireles M.C.A. (2013) In vitro activity of disinfectants against Aspergillus spp. Brazil. J. Microbiol. 44(2): 481-484. DOI: 10.1590/S1517-83822013000200024.

McDonnell G.A., Russell D. (1999) Antiseptics and disinfectants: activity, action, and resistance. Clin. Microbiol. Rev. 12(1): 147-179.

Mendoza P.C.G., Del-Toro G.V., Carrillo R.R., Martínez F.R., Fernández J.Y., Aguilar M.E.G., Hernández C.G., Villa G.B. (2014) Morphology and mycelial growth rate of Pleurotus spp. strains from the Mexican mixtec region. Brazil. J. Microbiol. 45(3): 861-872.

Mwangi R.W., Kariuki S.T., Wagara I.N. (2017) Biocontrol of green mould disease of oyster mushroom (Pleurotus ostreatus) using Bacillus amyloliquefaciens. J. Biol. Agric. Healthcare 7(10): 25-30.

Nanda S., Abraham J. (2013) Remediation of heavy metal contaminated soil. Afr. J. Biotechnol. 12(21): 3099-3109. DOI: 10.5897/AJB12.720.

Ndem J.U. Oku, Martha O. (2016) Mushroom production for food security in Nigeria. Food Sci. Qual. Manage. 48: 44-50.

Oberwinkler F. (2012) Evolutionary trends in Basidiomycota. Stapfia 96: 45-104.

Okore C.C., Mbanefo O.N., Onyekwere B.C., Onyewenjo S.C., Ozurumba A.U., Abba-Father C.A.M. (2014) Antimicrobial efficacy of selected disinfectants. Amer. J. Biol. Life Sci. 2(2): 53-57.

Olasehinde G.I., Akinyanju J.A., Ajayi A.A. (2008) Comparative antimicrobial activity of commercial disinfectants with naphtholics. Res. J. Microbiol. 3: 262-268. DOI: 10.3923/ jm.2008.262.268.

Orsi I.A., Villabona C.A., Kameoka E., Christiènne M., Ferreira C.G., Ito I.Y., Saraiva M.E. (2010) Antimicrobial efficacy of chemical disinfectants on contaminated full metal crowns. Brazil. Dental J. 21(3).

Peksen A., Kibar B., Yakupoglu G. (2013) Favourable culture conditions for mycelial growth of Hydnum repandum, a medicinal mushroom. Afr. J. Trad. Compl. Alternat. Med. 10(6): 431-434.

Reynolds K.A., Boone S., Bright K.. Gerba C.P. (2004) Efficacy of sodium hypochlorite disinfectant on the viability and allergenic properties of household mold. J. Allergy Clin. Immunol. 113(2): S180. DOI: 10.1016/j.jaci.2004. 01.082.

Rogawansamy S., Gaskin S., Taylor M.. Pisaniello D. (2015) An evaluation of antifungal agents for the treatment of fungal contamination in indoor air environments. Int. J. Environ. Res. Public Health 12(6): 6319-6332. DOI: 10.3390/ ijerph120606319.

Rosmiza M.Z., Davies W.P., Rosniza A.C.R., Jabil M.J., Mazdi M. (2016) Prospects for increasing commercial mushroom production in Malaysia: challenges and opportunities. Mediter. J. Social Sci. 7(1): 406-415. DOI: 10.5901/mjss. 2016.v7n1s1p406.

Rossi M.J., Furigo A., Oliveira V.L. (2007) Inoculant production of ectomycorrhizal fungi by solid and submerged fermentations. Food Technol. Biotechnol. 45(3): 277-286. 
Sánchez C. (2004) Modern aspects of mushroom culture technology. Appl. Microbiol. Biotechnol. 64: 756-762. DOI: 10.1007/s00253-004-1569-7.

Sardar H., Ali M.A., Ayyub Chaudhary M., Ahmad R. (2015) Effects of different culture media, temperature and $\mathrm{pH}$ levels on the growth of wild and exotic Pleurotus species. Pakistan J. Phytopathol. 27(02): 139-145.

Sharada M., Ashok J., Savitha H., Mahesh H., Nagaraj E.R. (2013) Comparative effectiveness of disinfectants with phenol on multidrug resistant bacteria and fungi isolated from the clinical sample - an in vitro preliminary study. J. Evolut. Med. Dental Sci. 2(18): 3055-3061. DOI: $10.14260 /$ jemds/659.

Sharma P.K., Singh F., Singh S., Dhawan A. (2018) Effect of physiological parameters on mycelial growth of blue oyster [Hypsizygus ulmarius (Bull.:Fr.) Redhead] mushroom. Intern. J. Curr. Microbiol. Appl. Sci. 7(6): 2440-2445.

Shuaibu A.S., Ibrahim Y.K.E., Olayinka B.O., Atata R.F., Shuaibu B.A., Salihu H.. Shuaibu M.G. (2017) Phenotypic resistance of nosocomial bacterial isolates to some routinely used disinfectants. World J. Pharmaceut. Med. Res. 3(7): $52-56$.

Singh M., Sharma R., Gupta P. K., Rana J.K., Sharma M., Taneja N. (2012) Comparative efficacy evaluation of disinfectants routinely used in hospital practice: India. Indian J. Crit. Care Med. 16(3): 123-129. DOI: 10.4103/0972-5229. 102067.

Soyemi E.T., Kolade A.F., Oluwadun A., Effedua H.I. (2018) In vitro activities of some common disinfectants on aspergillus fumigatus isolated from selected wards at the University College Hospital (UCH), Ibadan. Nature Sci. 16(9): 30-36.
Torres-Aquino M., Becquer A., Le Guernevé C., Louche J., Amenc L.K., Staunton S., Quiquampoix H., Plassard C. (2017) The host plant Pinus pinaster exerts specific effects on phosphate efflux and polyphosphate metabolism of the ectomycorrhizal fungus Hebeloma cylindrosporum: a radiotracer, cytological staining and $31 P$ NMR spectroscopy study. Plant, Cell Environ. 40: 190-202. DOI: $10.1111 /$ pce. 12847.

Uddin M.J., Nasiruddin K.M., Haque M.E., Biswas A.K., Islam M.S. (2012) Influence of different media variety and growth regulator on mycelial colony proliferation of mushroom. J. Environ. Sci. Natural Resour. 5(1): 223-227.

Valverde M.E., Pérez T.H., López O.P. (2015) Edible mushrooms: improving human health and promoting quality life. Intern. J. Microbiol. 2015, Article ID 376387: 14. DOI: $10.1155 / 2015 / 376387$.

Van Nieuwenhuijzen B. (2007) Small-scale mushroom cultivation - 2. Agromisa Foundation and CTA, Wageningen, Digiggrafi, Wageningen, the Netherlands. Agrodok-series No. 41. https://publications.cta.int/media/publications/ downloads/1422_POF.pdf.

Van Rooij P., Pasmans F., Coen Y., Martel A. (2017) Efficacy of chemical disinfectants for the containment of the salamander chytrid fungus Batrachochytrium salamandrivorans. PLoS One 12(10): e0186269. DOI: 10.1371/ journal. pone.0186269.

Wani B.A., Bodha R.H., Wani A.H. (2010) Nutritional and medicinal importance of mushrooms. J. Med. Plants Res. 4(24): 2598-2604. DOI: 10.5897/JMPR09.565.

Wijesinghe L.P., Weerasinghe T.K. (2010) A study on the bactericidal efficiency of selected chemical disinfectants and antiseptics. OUSL J. 6: 44-58. 